\title{
ENHANCEMENT OF DISSOLUTION RATE OF MECLOZINE HCI BY CO-GRINDING AND LOADING ONTO CERTAIN ADSORBENTS
}

\author{
A. E. Aboutaleb, A. A. Abdel-Rahman, M. O. Ahmed, U. S. Abu Uwaida
}

Department of Industrial Pharmacy, Faculty of Pharmacy, Assiut University, Assiut, Egypt

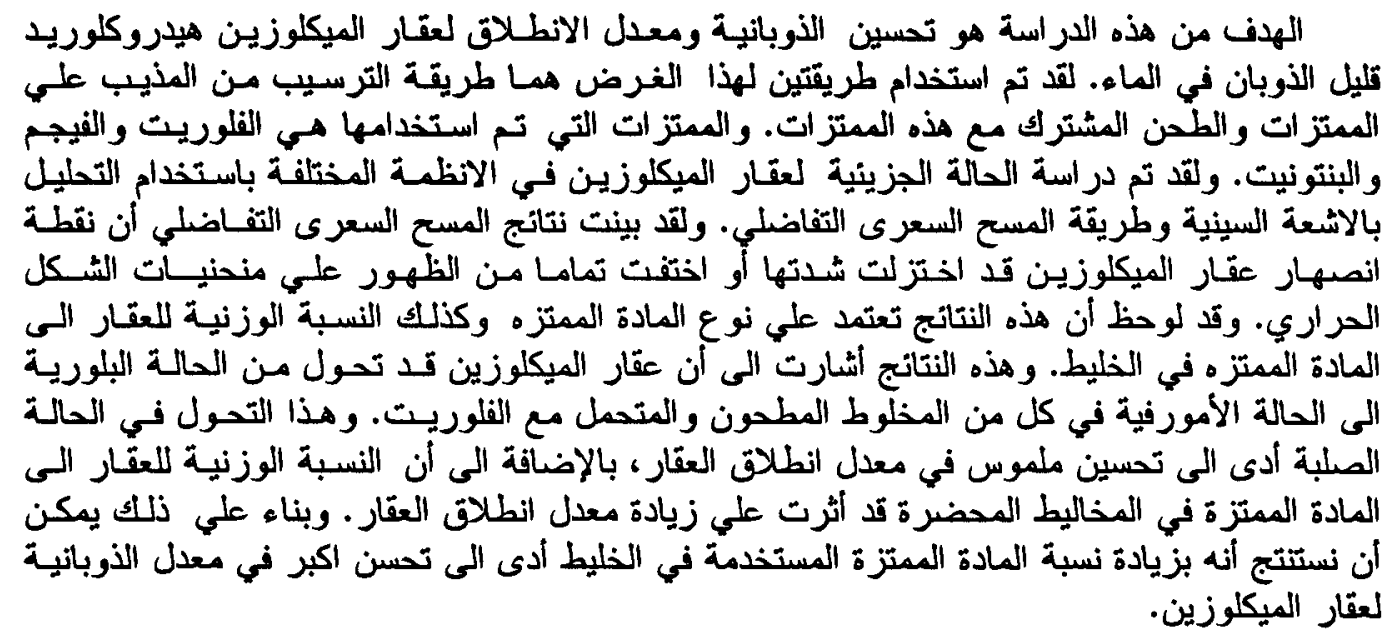

The aim of this work was to improve the solubility and dissolution rate of the sparingly water-soluble drug, meclozine hydrochloride (Mz). Two approaches were utilized namely, solvent deposition onto certain adsorbents and co-grinding with these adsorbents. Physical mixtures of $M z$ with the investigated adsorbents were also prepared. The used adsorbents were porous silica (Florite $($ ), veegum and bentonite. The molecular behovior of $\mathrm{Mz}$ in the investigated systems were studied using $X$-ray diffraction analysis and differential scanning calorimetry (DSC). The DSC results showed that the drug melting peak was reduced in intensity or disappeared totally in the obtained thermograms. This was noticed to be dependent on the adsorbent type as well as the weight ratio of the drug to the adsorbent in the mixture. The obtained results indicated that $M z$ was transformed from the crystalline to the amorphous state in both the ground and the loaded mixtures with Florite $\mathbb{B}$. This transformation resulted in a significant enhancement in the dissolution rate of the drug. In addition, it was noticed that the drug: adsorbent weight ratio of the prepared mixtures influenced the drug dissolution rate enhancement. Accordingly, it can be concluded that by increasing the weight ratio of the used adsorbent in the mixture, the larger the enhancement in the dissolution rate of $M z$ was obtained.

\section{INTRODUCTION}

Meclozine hydrochloride $(\mathrm{Mz})$ is an antihistaminic drug that shows marked protective activity against nebulized histamine. It is indicated in the management of nausea, vomiting and dizziness associated with motion sickness, and it has been found useful in the management of vertigo associated with diseases affecting the vestibular system. ${ }^{1}$ However, $\mathrm{Mz}$ is only slightly soluble in water, ${ }^{2}$ as a result of which the drug may exhibit poor absorption characteristics.

Several techniques have been successfully used to improve the dissolution rates of poorly water-soluble drugs. These techniques include solid dispersions with various carriers, ${ }^{3-6}$ solvent deposition, ${ }^{7}$ solid solution, ${ }^{8}$ co-grinding with certain carriers, ${ }^{9,10}$ lyophilization ${ }^{11}$ and surface hydrophilization. $^{10,12}$ The use of bile salts, ${ }^{13}$ gelatin, ${ }^{14}$ egg Albumin, ${ }^{15}$ cyclodextrins ${ }^{16,17}$ and hydroxypropylmethyl cellulose ${ }^{18}$ has also been 
reported to enhance the dissolution of variety of poorly soluble drugs.

Adsorbents have been used as carriers in order to increase the solubility and dissolution rate of drugs having poor aqueous solubility. ${ }^{19}$ As they have a large surface relative to their volume, drugs are adsorbed onto the adsorbent surface in a molecular form, accordingly their particle size is decreased and hence, their water solubility is enhanced. ${ }^{20}$ Among the mostly used adsorbents are veegum, ${ }^{21}$ bentonite and silicates, in addition to some disintegrents. ${ }^{22}$ Besides, some adsorbents have a pharmacological activity such as veegum, kaolin and magnesium trisilicate. $^{20}$ Silicates $^{10}$ are of outstanding importance as carriers in solid, semisolid and liquid dosage forms for their excellent physicochemical properties. Florite is a novel porous calcium silicate. It has a large surface area, good flowability and excellent mouldability. Moreover, it is a pure synthetic inorganic unabsorbable material so that it is considered safe for oral administration. ${ }^{23}$ Molecular dispersions of drugs onto the extremely large surface area of porous silica have been utilized for improving dissolution rates and absorption of several poorly soluble drugs. ${ }^{23,24}$

The present work aimed to enhance the dissolution rate of $\mathrm{Mz}$ using simple and economic techniques.

\section{EXPERIMENTAL}

\section{Materials}

Meclozine $\mathrm{HCl}(\mathrm{Mz})$, (a gift from Chemical Industries Development, CID-Egypt) was used as received. Porous silica Florite (Tokuyama Soda, Co., Japan) was used after drying at $120^{\circ}$ for three hours in an oven under vacuum. Bentonite and veegum (Nile Company for Pharmaceutical and Chemical Industry, Egypt) were used as received. All other materials and solvents were of analytical grades.

\section{Methods}

Preparation of the physical mixtures

The physical mixtures of the drug with the used adsorbents $(125-250 \mu \mathrm{m})$ at three different weight ratios (1:2, 1:1 and 2:1 drug: adsorbent weight ratios) were prepared by simple mixing of the required amounts of drug and carrier using a pestle and a mortar.

\section{Preparation of the ground mixtures}

The ground mixtures were prepared at the different drug: carrier weight ratios using a vibrational uniball mill by grinding their physical mixtures (VEB leuchtenbau-KMl, Germany).

\section{Preparation of the loaded mixtures}

The required amounts of $\mathrm{Mz}$ were dissolved in ethanol $(40 \mathrm{ml})$. The drug solutions were then added to the required amount of the adsorbent to give the desired drug: adsorbent weight ratio. Ethanol was evaporated in an oven at $40^{\circ}$ under vacuum (SPT. 200 vacuum oven drier-Poland).

\section{$X$-ray diffraction studies}

The X-ray diffraction patterns for $\mathrm{Mz} /$ Florite $^{\circledR}$ ground mixtures were determined using Philips 1710 diffractometer (Germany) operating at a scanning speed of $0.6 \% \mathrm{~min}$ and a wide angle diffraction of $4^{\circ}<2 \theta<50^{\circ}$.

\section{Differential scanning calorimetry (DSC)}

A Shimadzu DSC-50 (Japan) was used for carrying out the DSC of the investigated samples. The measurements were performed at a heating rate of $10 \% \mathrm{~min}$. under $\mathrm{N}_{2}$ gas flow of 40 $\mathrm{ml} / \mathrm{min}$, using aluminum hermetically sealed sample pans. The sample weight was about 4-5 $\mathrm{mg}$

\section{Dissolution studies}

The dissolution rates of $\mathrm{Mz}$ from the prepared mixtures were determined using Hanson dissolution test station (Hanson Researches-California, USA). The dissolution medium was $900 \mathrm{ml}$ of $0.1 \mathrm{~N} \mathrm{HCl}(\mathrm{pH}$ 1.2) stirred at $100 \mathrm{rpm}$ and maintained at $37 \pm 0.5^{\circ}$. A quantity of $25 \mathrm{mg}$ of the drug or an equivalent amount of the prepared mixtures was sprinkled on the dissolution medium. Samples of $5 \mathrm{ml}$ were withdrawn at specified time intervals and replaced by an equal volume of the same dissolution medium kept at $37 \pm 0.5^{\circ}$. The amounts of the dissolved drug were determined spectrophotometrically at $230 \mathrm{~nm}$ (UVIDEC320 spectrophotometer, JAS. Co, Japan). It was found that non of the adsorbents interfered with the assay. Each experiment was performed at least three times and the mean was calculated in each case. 


\section{RESULTS AND DISCUSSION}

Fig. (1) shows the X-ray diffraction patterns of some Mz/Florite ${ }^{\circledR}$ systems. The untreated drug, (trace A), showed crystalline characteristic peaks, particularly at $2 \theta=20.65$, $20.86,25.32,25.56,26.25$ and $28.21^{\circ}$. Florite, (Fig. 1, trace E), has no characteristic X-ray diffraction peaks due to its highly amorphous structure. From the obtained results, it can be noticed that the characteristic X-ray diffraction peaks of the drug were reduced to a large extent

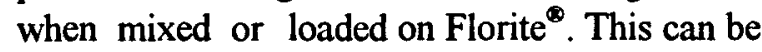
attributed to the transformation of $\mathrm{Mz}$ from the crystalline state to an amorphous state when it was adsorbed onto the surface of Florite ${ }^{\text {. Also }}$ it can be noticed that this transformation depends on the ratio of $\mathrm{Mz}$ to Florite ${ }^{\otimes}$ in the mixture. Accordingly, increasing the Florite ratio in the mixture led to producing a highly amorphous state of $\mathrm{Mz}$. ${ }^{10,24}$

Fig. (2) shows the DSC thermograms of the loaded mixtures of $\mathrm{Mz}$ with Florite ${ }^{\circledR}$ at different drug: adsorbent weight ratios. Untreated $\mathrm{Mz}$ has a single endothermic peak at $232.7^{\circ}$ as a result of the melting of the drug. When $\mathrm{Mz}$ was loaded onto the surface of Florite $^{\circledR}$, this peak has been totally disappeared in those systems, as shown in Fig. (2), curves (C-E). This can be attributed to the transformation of $\mathrm{Mz}$ from the crystalline state into a highly amorphous state when it was adsorbed onto the adsorbent surface..$^{25}$ In case of $\mathrm{Mz} /$ Florite $^{\otimes}$ co-grinding and physical mixtures (Fig. 3), the drug endothermic peak was reduced in intensity to a large degree, depending on the weight ratio of the drug to the Florite ${ }^{\otimes}$ in the mixture. So it was noticed that the drug endothermic peak was reduced in systems of the composition 2:1 weight ratio (drug: Florite ${ }^{\otimes}$ ), while this peak has been disappeared when higher drug: Florite ${ }^{\circledR}$ ratios were used (i.e. 1:1 and 1:2 drug: Florite ${ }^{8}$ weight ratio).

Almost the same results of DSC were obtained in case of veegum loaded mixtures, (Fig. 4). But in this case, the drug melting endothermic peak has not disappeared totally in the case of 2:1 drug: veegum system, although it was reduced in intensity to a large extent. This could be attributed to the fact that veegum is less porous than Florite and hence, the lower adsorbing capacity of veegum compared to that of Florite ${ }^{\circledR}$.
In case of $\mathrm{Mz}$ /bentonite systems (Fig. 5), the drug endothermic peak was reduced gradually in intensity by increasing the ratio of bentonite but did not disappear completely except in case of 1:2 Mz: bentonite weight ratio (curve F). This may be attributed to the limited surface area of bentonite in comparison to that of Florite $^{\infty}$ accordingly the observed endothermic peaks may be due to melting of excess drug molecules.

These results are in good agreement with the obtained values of enthalpy change (i.e. $\Delta H$ of fusion) of $\mathrm{Mz}$ determined from the DSC thermograms. It was noticed from these data that $\Delta H$ values were equal to zero in case of

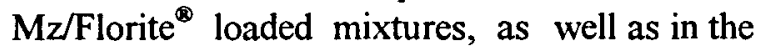
1:2 (drug : adsorbent weight ratio), $\mathrm{Mz}$ : veegum or bentonite systems. On the other hand, the value of $\Delta \mathrm{H}$ decreased to a great extent in the other prepared systems compared to that of the untreated drug. The change in the value of $\Delta \mathrm{H}$ was dependent on the weight ratio of the adsorbent to that of the drug in the mixture. Accordingly, this value decreased as the ratio of the adsorbent was increased in the prepared systems. These results revealed that $\mathrm{Mz}$ was transformed from its crystalline state into a highly amorphous state when it was adsorbed onto the surfaces of the different used adsorbents. ${ }^{26}$

The dissolution behavior of $\mathrm{Mz}$ from the prepared systems with Florite ${ }^{\otimes}$, veegum and bentonite at $\mathrm{pH} 1.2$ are illustrated in Figs (610). Fig. 6 shows the dissolution profiles of $\mathrm{Mz}$ from the prepared $\mathrm{Mz} /$ Florite $^{\circledR}$ systems having 1:2 (drug: adsorbent) weight ratio. It is clear that the dissolution rate of $\mathrm{Mz}$ has been largely enhanced especially in cases of ground and physical mixtures. On increasing the concentration of $\mathrm{Mz}$ from 1:2 (drug: Florite ${ }^{\circledR}$ ) weight ratio to $1: 1$ (Fig. 7) or 2:1 (Fig. 8), the dissolution rate was decreased. These results indicated good correlation between the dissolution rate of the drug and its molecular state. Accordingly, increasing the Florite ratio in the mixture led to transformation of the drug from the crystalline state into the amorphous state, and the higher the concentration of Florite in the mixture, the more amount of the drug will be transformed into the amorphous state. $^{10}$ 


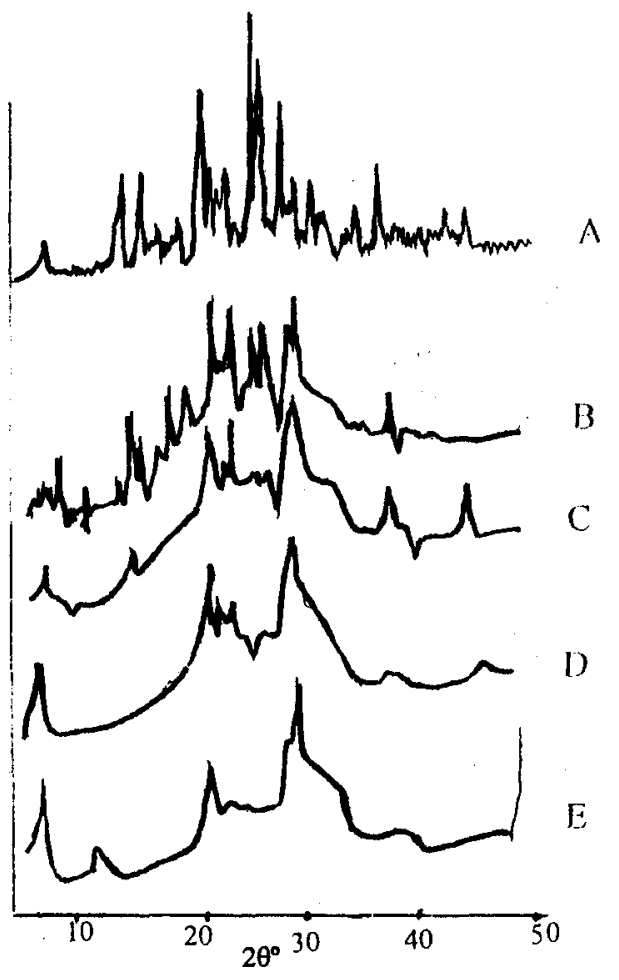

Fig. 1: X-ray diffraction patterns for Mz/Florite ground mixtures systems.

A) $\mathrm{Mz}$ alone, B) 2:1 ground mixtures, C) 1:1 ground mixture, D) 1:2 ground mixture, E) Florite ${ }^{\star}$ alone.

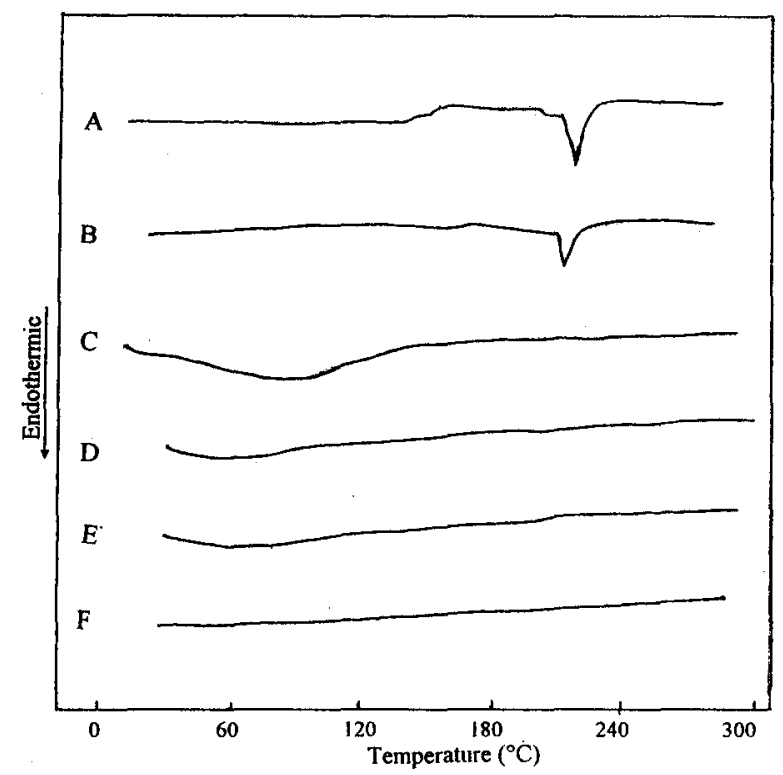

Fig. 2: DSC thermograms for Mz/Florite ${ }^{\otimes}$ loaded mixtures.

A) $\mathrm{Mz}$ alone, B) $\mathrm{Mz}$ recrystallized from ethanol, C) 2:1 loaded mixture, D) $1: 1$ loaded mixture, E) 1:2 loaded mixture, F) Florite $^{\circledast}$ alone.

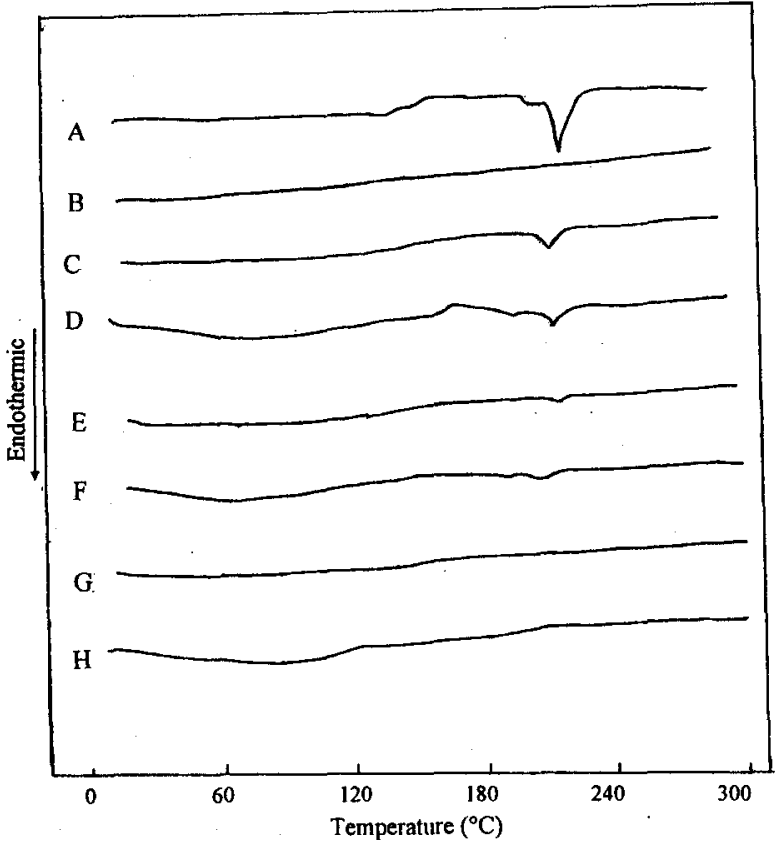

Fig. 3: DSC thermograms for Mz/Florite ground and physical mixtures.

A) $\mathrm{Mz}$ alone, B) Florite ${ }^{\infty}$ alone, C) $2: 1$ physical mixture, D) 2:1 ground mixture, E) 1:1 physical mixture, F) 1:1 ground mixture, G) 1:2 physical mixture, H) 1:2 ground mixture.

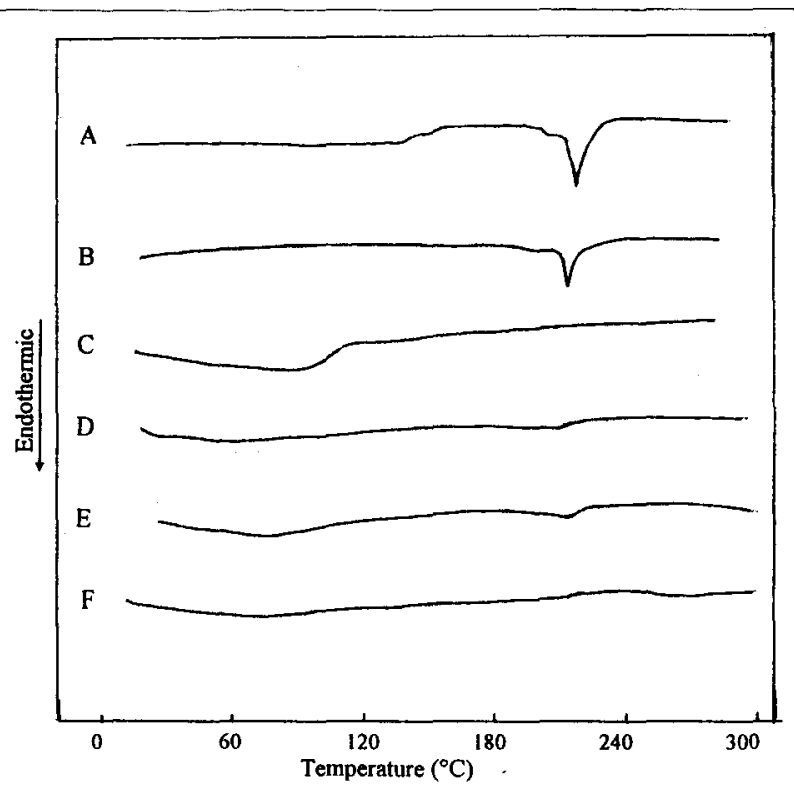

Fig. 4: DSC thermograms for Mz/veegum loaded mixtures.

A) $\mathrm{Mz}$ alone, B) recrystallized from ethanol, C) veegum alone, D) 1:1 loaded mixture, E) 2:1 loaded mixture, F) 1:2 loaded mixture. 


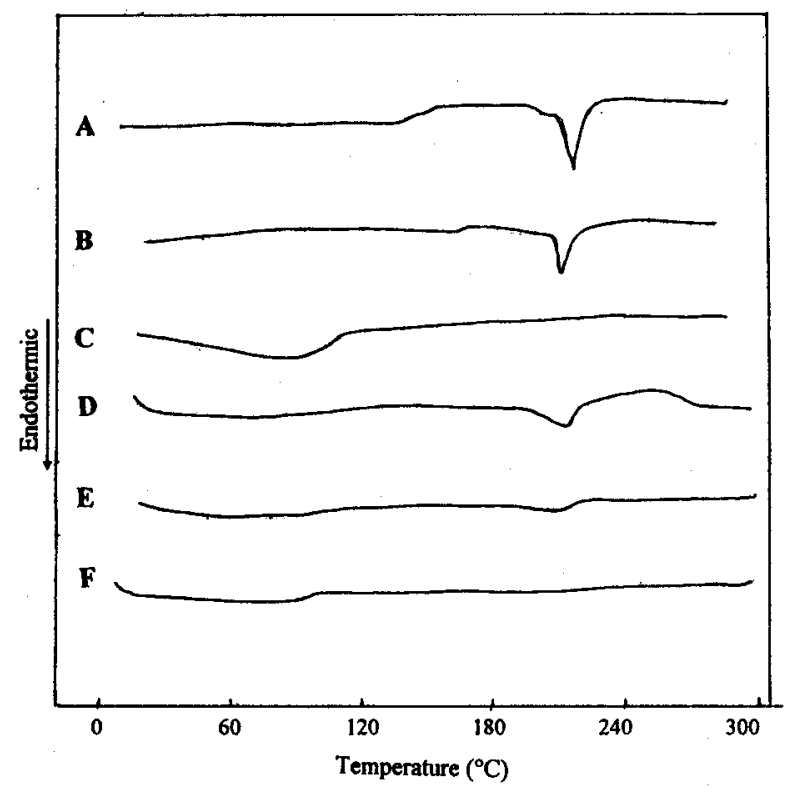

Fig. 5: DSC thermograms for Mz/bentonite loaded mixtures.

A) $\mathrm{Mz}$ alone, B) $\mathrm{Mz}$ recrystallized from ethanol, C) bentonite alone, D) 2:1 loaded mixture, E) 1:1 loaded mixture, F) 1:2 loaded mixture.

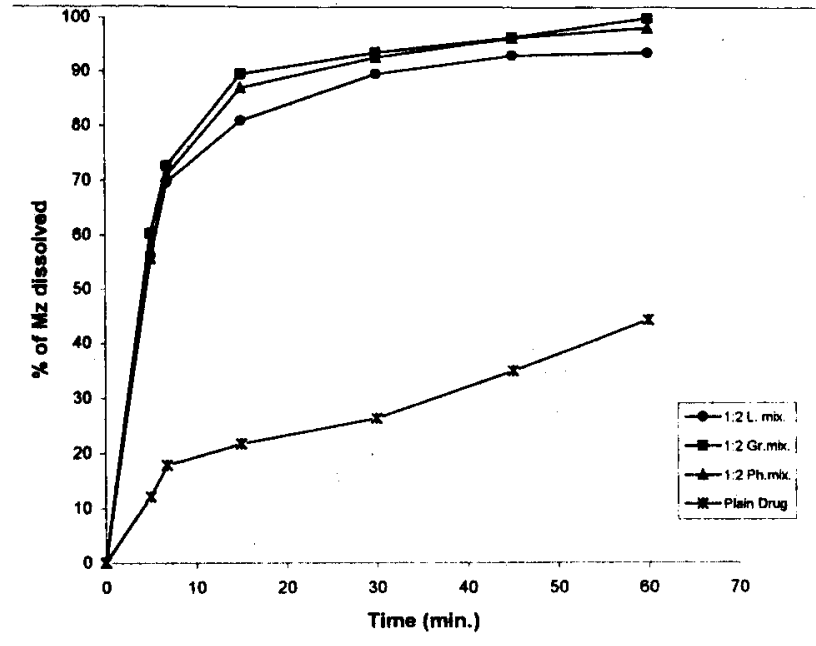

Fig. 6: Release profiles of $\mathrm{Mz}$ from Mz/Florite prepared systems in 1:2 (Drug: Florite) weight ratio in $0.1 \mathrm{~N} \mathrm{HCl}$ at $37^{\circ}$.

Note: Gr.mix= ground mixture; L.mix= loaded mixture; $\mathrm{Ph} . \mathrm{mix}=$ physical mixture.

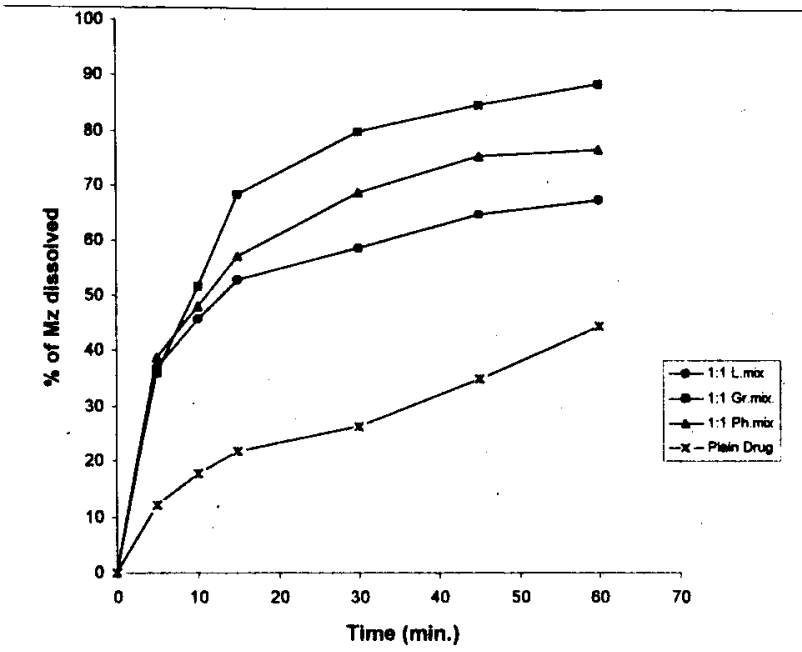

Fig. 7: Release profiles of $\mathrm{Mz}$ from Mz/Florite prepared systems in 1:1 (drug : Florite) weight ratio in $0.1 \mathrm{~N} \mathrm{HCl}$ at $37^{\circ}$.

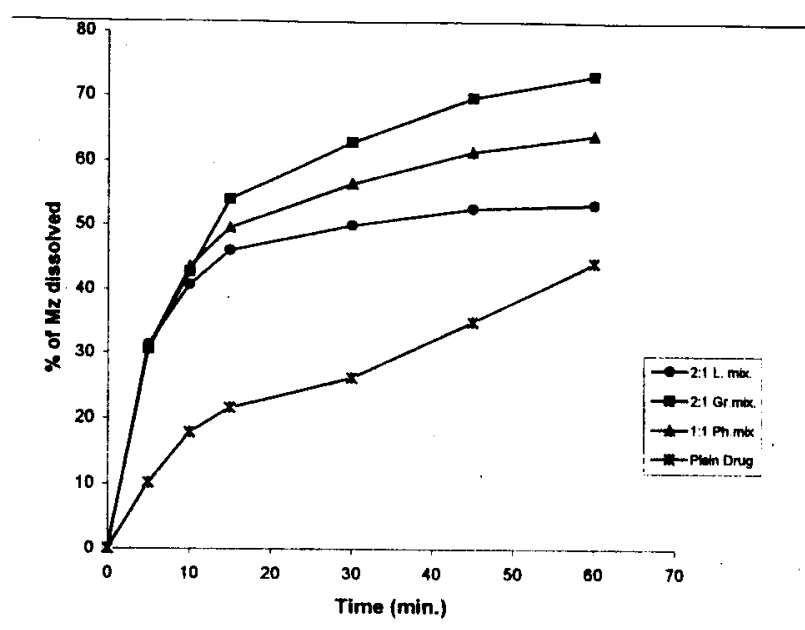

Fig. 8: Release profiles of $\mathrm{Mz}$ from $\mathrm{Mz} /$ Florite $^{\circ}$ prepared systems in 2:1 (drug : Florite ${ }^{*}$ ) weight ratio in $0.1 \mathrm{~N} \mathrm{HCl}$ at $37^{\circ}$. 


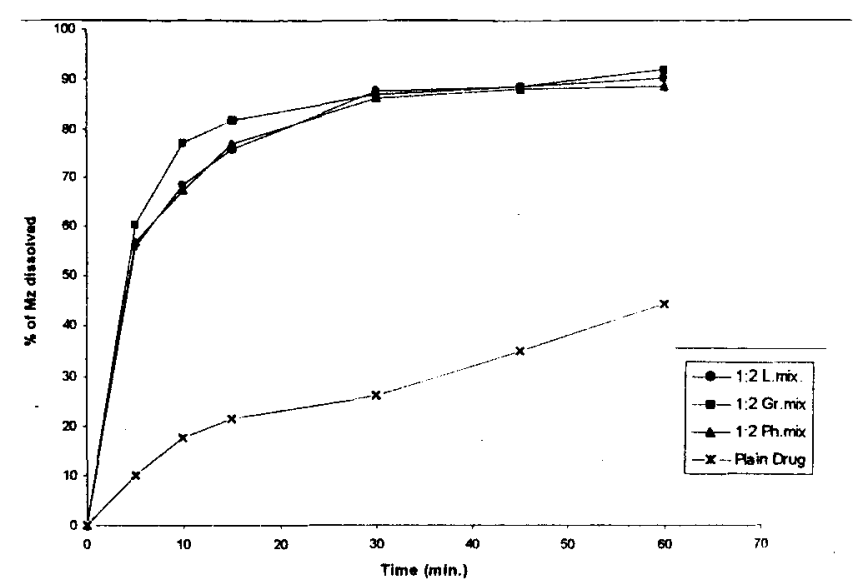

Fig. 9: Release profiles of $\mathrm{Mz}$ from $\mathrm{Mz} /$ veegum prepared systems in 1:2 (drug: veegum) weight ratio in $0.1 \mathrm{~N} \mathrm{HCl}$ at $37^{\circ}$.

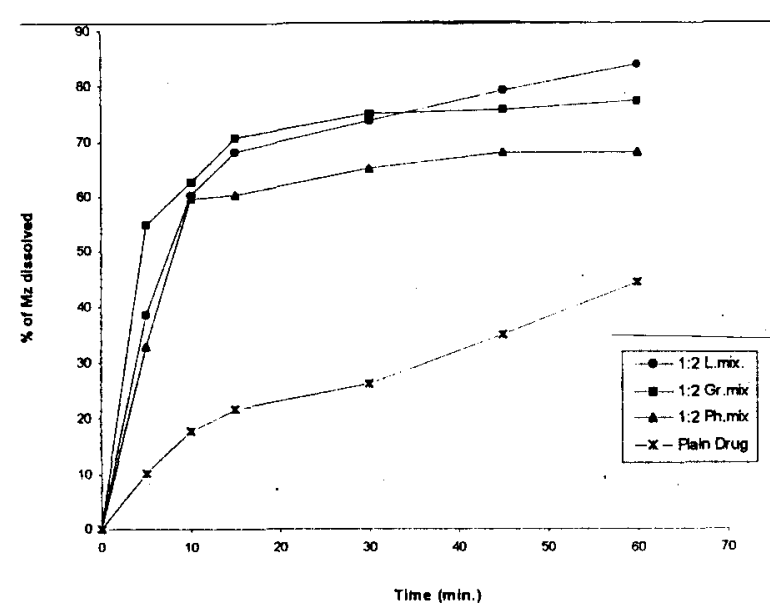

Fig. 10: Release profiles of $\mathrm{Mz}$ from $\mathrm{Mz}$ /bentonite prepared systems in 1:2 (drug : bentonite) weight ratio in $0.1 \mathrm{~N} \mathrm{HCl}$ at $37^{\circ}$.

Table 1: $\mathrm{T}_{50 \%}$ and $\mathrm{RDR}$ values for different $\mathrm{Mz} /$ adsorbent systems.

\begin{tabular}{|c|c|c|c|c|}
\hline \multirow[t]{2}{*}{ System } & \multirow[t]{2}{*}{$\mathrm{T}_{50 \%}(\min )}$. & \multicolumn{3}{|c|}{ RDR valué at time (min.) } \\
\hline & & 10 & 30 & 60 \\
\hline Plain drug & 75.0 & 1.0 & 1.0 & 1.0 \\
\hline $\begin{array}{c}\text { Mz/Florite }{ }^{\otimes} \text { loaded mixture } \\
2: 1 \\
1: 1 \\
1: 2 \\
\end{array}$ & $\begin{array}{c}30.0 \\
13.0 \\
4.5 \\
\end{array}$ & $\begin{array}{l}2.3 \\
2.5 \\
3.9 \\
\end{array}$ & $\begin{array}{l}1.9 \\
2.2 \\
3.4 \\
\end{array}$ & $\begin{array}{l}1.2 \\
1.5 \\
2.2\end{array}$ \\
\hline $\begin{array}{c}\text { Mz/Florite }{ }^{\otimes} \text { ground mixture } \\
2: 1 \\
1: 1 \\
1: 2\end{array}$ & $\begin{array}{l}13.0 \\
10.0 \\
4.0 \\
\end{array}$ & $\begin{array}{l}2.4 \\
2.9 \\
4.1 \\
\end{array}$ & $\begin{array}{l}2.4 \\
3.0 \\
3.6 \\
\end{array}$ & $\begin{array}{l}1.7 \\
2.0 \\
2.2 \\
\end{array}$ \\
\hline $\begin{array}{c}\mathrm{Mz} \text {-Florite }{ }^{\circledR} \text { physical mixture } \\
2: 1 \\
1: 1 \\
1: 2\end{array}$ & $\begin{array}{l}14.0 \\
11.0 \\
4.0\end{array}$ & $\begin{array}{l}2.4 \\
2.7 \\
4.0\end{array}$ & $\begin{array}{l}2.2 \\
2.6 \\
3.5\end{array}$ & $\begin{array}{l}1.4 \\
1.7 \\
2.2\end{array}$ \\
\hline $\begin{array}{c}\mathrm{Mz} / \text { veegum physical mixture } \\
2: 1 \\
1: 1 \\
1: 2\end{array}$ & $\begin{array}{c}18.0 \\
9.0 \\
4.0\end{array}$ & $\begin{array}{l}2.5 \\
3.0 \\
4.3\end{array}$ & $\begin{array}{l}2.1 \\
2.7 \\
3.3\end{array}$ & $\begin{array}{l}1.5 \\
1.7 \\
2.1\end{array}$ \\
\hline $\begin{array}{c}\text { Mz/bentonite physical mixture } \\
2: 1 \\
1: 1 \\
1: 2 \\
\end{array}$ & $\begin{array}{c}13.5 \\
8.75 \\
4.5 \\
\end{array}$ & $\begin{array}{l}2.0 \\
3.2 \\
3.5 \\
\end{array}$ & $\begin{array}{l}2.2 \\
2.5 \\
2.8\end{array}$ & $\begin{array}{l}1.4 \\
1.6 \\
1.8 \\
\end{array}$ \\
\hline
\end{tabular}


From the obtained results, it can be seen that the dissolution rate of $\mathrm{Mz}$ from Florite systems was superior to dissolution rates obtained from veegum or bentonite systems, (Figures 9 and 10, respectively). This could be attributed to the large surface area of Florite on which the drug molecules can be adsorbed, compared to that of veegum and bentonite. However, the increase in drug dissolution rate was much higher in the first 15 minutes of the experiment as it reached to about four times the dissolution rate of the intact drug in case of the physical mixture with Florite ${ }^{\star}$. These results as well as the $T_{50 \%}$ values and the relative dissolution rate enhancement (RDR) are shown in Table (1).

The observed enhancement in the drug dissolution rate can be attributed to any or combination of the following reasons:

a. The mono-molecular adsorption of $\mathrm{Mz}$ molecules onto the large surface area of the adsorbents via hydrogen bonding and van der Waal's forces.

b. Reduction of the drug particle size and hence increasing its surface area exposed to the dissolution medium.

c. Reduction of $\mathrm{Mz}$ crystallinity and converting it to an amorphous state as a result of its adsorption on the adsorbents surfaces.

d. The high dissolution rate of $\mathrm{Mz}$ could be also attributed to the rapid desorption of the physically adsorbed $\mathrm{Mz}$ molecules when these mixtures were placed in the dissolution medium. The dissolution is therefore different from that of the pure drug, where dissolution occurs from the surface of the drug crystals according to the concentration gradient. ${ }^{10}$

\section{REFERENCES}

1- S. Kenneth, Jr. Babe and E. William, "Goodman and Gilman's: The Pharmacological Basis of Therapeutics" $9^{\text {th }}$ ed. (1996).

2- USP XXXIII Ed., Convention, Inc., Rock Ville, Md., (1995).

3- P. Sheen, V. K. khetarpal, C. M. Cariola and C. E. Rowlings, Int. J. Pharm., 118, 221 (1997).
4- H. O. Ammar, M. Ghorab, S. A. ElNahhas and T. S. Makram, Pharmazie, 52, 627 (1997).

5- M. C. Martinez-Oharriz, C. Martin, M. M. Goni, C. Rodriguez-Espinosa, M. C. TrosIlarduya and A. Zornoza, Eur. J. Pharm. Sci., 8 (1999).

6- H. O. Ammar and R. M. Khalil, Drug Dev. Ind. Pharm., 23, 11 (1997).

7- Shu-Yang Yen, Chun-Ren Chen, Ming-Tao Lee and Li-Chen Chen, Drug Dev. Ind. Pharm., 23, 3 (1997).

8- A. Sheth and C. I. Jarowski, Drug Dev.Ind. Pharm., 16, 769 (1990).

9- Y. Nakai, Drug Dev. Ind. Pharm., 12, 1017, (1986).

10- A. S. Ali, Bull. Pharm. Sci., Assiut Univ., Vol. 20 (1), 1 (1997).

11- G. V. Betageri and K. R. Makarla, Int. J. Pharm., 126, 155 (1995).

12- S. A. Ibrahim, T. H. El-Faham, E. Hafez and F. A. Mohammed, Pharm. Ind., 53, 401 (1991).

13- J. H. De Smidt, J. C. Offringa and D. J. Crommelin, J. Pharm. Sci., 80, 399 (1991).

14- M. Fujii, M. Hioki, M.Nishi, T. Henmi and M. Matsumoto, Chem. Pharm. Bull., 41, 1275 (1993).

15- A. S. Kearney, D. L. Gabriel, S. C. Mehta and G. W. Radebaugh, Int. J. Pharm., 104, 164 (1994).

16- H. O. Ammar, S. A. El-Nahhas and R. M. Khalil, Pharmazie, 53, 11 (1998).

17- T. Lftsson and D. S. Peterson, Pharmazie, 53, 10 (1997).

18- H. Yuasa, H. Takahashi, T. Ozeki, Y. Kanaya and M. Ueno, Chem. Pharm. Bull., 41, 397 (1993).

19- A. S. Ali, Ph.D. Thesis, Assiut Univ. (1992).

20- H. Ahmed, McS Thesis, Assiut Univ. (1997).

21- H. A. Koeleman, R. van Zyl, N. Steyn, B.Boneschans and H.S. Steyn, Drug Dev. Ind. Pharm., 16, 5 (1990).

22- S. L. Law and C. H. Chiang, Drug.Dev. Ind. Pharm., 16, 1 (1990).

23- A. M. El-Sayed, A. S. Ali and A. A. Assi, S.T.P., Pharma, 3, 319 (1993).

24- S. M. Safwat, A. S. Ali, M. O. Ahmed and I. Abdel-Sabour, Bull. Pharm. Sci., Assiut Univ., 17, 139 (1994). 
25- Y. Nakai, E. Fukuka, S. Nakajima and K. Yamamoto, Chem. Pharm. Bull., 25, 3340 (1977).
26- N. M. Najib and M. S. Suleiman, Int. J. Pharm., 51, 225 (1989). 